\title{
СОВРЕМЕННЫЕ ПОДХОДЫ К ОПРЕДЕЛЕНИЮ ПОНЯТИЯ «ИНФОРМАЛЬНОЕ ОБРАЗОВАНИЕ»
}

\author{
Т. В. Лискина', Н. С. Паульзен² \\ 1 Рязанский государственный университет им. С. А. Есенина, г. Рязань, Российская Федерация \\ ${ }^{2}$ Байкальский государственный университет, г. Иркутск, Российская Федерация
}

Информация о статье

Дата поступления

2 декабря 2017 г.

Дата принятия к печати 28 февраля 2018 г.

Дата онлайн-размещения 30 марта 2018 г.

\section{Ключевые слова}

Информальное образование; образование; образование шириною в жизнь

\begin{abstract}
Аннотация
В статье рассматривается проблематика определения понятия «информальное образование» в отечественной и зарубежной литературе, различные взгляды ученых на информальную сторону образования, а также классифицируются подходы к определению места и результатов данного вида образования в системе образования. Авторы выделяют проблемные поля информального образования: низкая мотивация учащихся, недостаточный объем методических указаний и чувство неуверенности при использовании полученных знаний. В статье представлен сопоставительный анализ таких образовательных единиц, как самообучение и информальное образование, который позволяет сделать вывод о взаимозависимости данных понятий и структуре некой «матрешки»: самообучение - самообразование - неформальное образование - информальное образование. В качестве цели работы выступает систематизация подходов к определению информального образования, его уточнение с авторской точки зрения, определение места и значения информального образования в процессе обучения в высшей школе.
\end{abstract}

\section{MODERN APPROACHES TO THE DEFINITION OF «INFORMAL EDUCATION»}

\author{
Tamara V. Liskina ${ }^{1}$, Natalia S. Paulsen ${ }^{2}$ \\ 1 S. A. Yesenin Ryazan State University, Ryazan, the Russian Federation \\ ${ }^{2}$ Baikal State University, Irkutsk, the Russian Federation
}

Article info

Received

December 2, 2017

Accepted

February 28, 2018

Available online

March 30, 2018

\section{Keywords}

Informal education; education; life-wide learning

\begin{abstract}
The article is dedicated to the problems of defining the term «informal education» in Russian and foreign literature, different views of scientists on the informal aspect of education, and classifies approaches to determining the place and results of this type of education in the education system. The authors single out problem fields of informal education: low motivation of students, insufficient volume of methodological instructions and a feeling of uncertainty when using the acquired knowledge. The authors present a comparative analysis of 'self-training' and 'informal education', which allows making a conclusion about the interdependence of these concepts in a nestling doll-type structure: self-training - self-education - non-formal education - informal education. The goal of the article is to systematize the approaches to the definition of informal education, to clarify it with the author's point of view; to analyze the place and value of informal education in higher education.
\end{abstract}

В последние годы вектор всех образовательных процессов направлен на Болонский процесс и связанные с ним новации. В связи с этим в педагогической лексике прочно закрепилось использование термина «образование шириною в жизнь», объединяющего в себе формальное, неформальное и информальное образование. Перечисленные выше виды образования напоминают, что обучение может быть полезным и приятным и происходить как в образовательном учреждении, так и в компании друзей, на занятиях в кружках и секциях, 
при общении в Интернете, чтении книг и журналов, просмотре научных и художественных фильмов и т. д. И сейчас мы можем говорить о том, что неформальное и информальное образование становятся равноправными элементами процесса освоения знаний [1, с. 94]. Так, по словам О. А. Митусовой, «фрормальное и неформальное образование есть практически в каждом вузе. Что касается информального образования, его часто не принимают во внимание. Однако информальное образование может явиться толчком для изучения/исследования важной проблемы, расширяет общий и научный кругозор, дает установку для дальнейшей деятельности» [2, с. 175].

Анализ литературы и научных трудов с целью определения понятия информального образования показывает, что не существует четкой дефиниции данного термина. Это связано с несколькими причинами:

- относительная «молодость» концепции информального образования (понятие было окончательно внедрено в США в 1970-1980е гг., а в Европе с 2000-х гг. после издания Меморандума о непрерывном образовании Европейского союза');

${ }^{1}$ Меморандум непрерывного образования ЕС 2000 г. URL: http: //www.znanie.org/docs/memorandum.html.
- понятие трактуется в контексте авторских позиций, авторских научных школ, иногда противоречащих друг другу;

- информальное образование не может рассматриваться вне контекста формального и неформального образования, так как они составляют единую образовательную парадигму современного мира и представляют собой современный образовательный процесс, однако дебаты относительно определения этих понятий содержат зачастую противоречивые заявления о превосходстве одного типа обучения над другим;

- дефиниция понятия информального образования зависит от исторически сложившихся национальных систем образования [3].

В таблице на основе обзора различных подходов современных отечественных и зарубежных ученых-лингвистов к определению понятия информального образования авторы статьи постарались выделить и систематизировать основные идеи и представления по поводу этого актуального для образовательного процесса явления.

Подходы к определению понятия «информальное образования»

\begin{tabular}{|c|c|c|}
\hline $\begin{array}{c}\text { Автор подхода, } \\
\text { источник информации }\end{array}$ & Определение понятия & Подход \\
\hline $\begin{array}{l}\text { Меморандум непре- } \\
\text { рывного образования } \\
\text { EC } 2000 \text { г. }\end{array}$ & $\begin{array}{l}\text { Информальное образование можно трактовать как «индивидуаль- } \\
\text { ную познавательную деятельность, сопровождающую повседнев- } \\
\text { ную жизнь и не обязательно носящую целенаправленный характер» }\end{array}$ & Деятельность \\
\hline $\begin{array}{l}\text { Я. Кузьминов, } \\
\text { И. Фрумин и др. } \\
{[4, \text { с. } 33]}\end{array}$ & $\begin{array}{l}\text { Информальное образование есть «спонтанное образование, } \\
\text { которое реализуется за счет собственной активности индивидов } \\
\text { в насыщенной культурно-образовательной среде» }\end{array}$ & Образование \\
\hline Словарь терминов ${ }^{2}$ & $\begin{array}{l}\text { Информальное образование - полученное в повседневной жизни } \\
\text { без ясно установленных целей; «непрерывный процесс формиро- } \\
\text { вания у каждого человека отношений, ценностей, навыков и знаний } \\
\text { в результате ежедневных событий, воспитательных воздействий } \\
\text { и окружающей среды - семьи и соседей, работы и игры, рынка, } \\
\text { библиотек, средств массовой информации» }\end{array}$ & Процесс \\
\hline М. Тайт [5] & $\begin{array}{l}\text { Информальное образование трактуется как «формы обучения, } \\
\text { не включенные в формальное и неформальное образование, так, } \\
\text { например, различные виды образовательного влияния общества - } \\
\text { работы, дома, семьи, друзей, СМИ, книг» }\end{array}$ & $\begin{array}{l}\text { Форма } \\
\text { обучения }\end{array}$ \\
\hline $\begin{array}{l}\text { Ш. Мерриам, } \\
\text { Р. Кафррарелла [6, р. 21] }\end{array}$ & $\begin{array}{l}\text { Информальное образование выступает как «опыт каждодневной } \\
\text { жизни, который нас чему-то обучает» }\end{array}$ & $\begin{array}{l}\text { Жизненный } \\
\text { опыт }\end{array}$ \\
\hline $\begin{array}{l}\text { С. Г. Вершловский } \\
\text { (российский педагог, } \\
\text { доктор педагогических } \\
\text { наук, профессор, } \\
\text { специалист в области } \\
\text { андрагогики и непре- } \\
\text { рывного образования) } \\
\text { [7, с. 11-12] }\end{array}$ & $\begin{array}{l}\text { «Информальное образование - (находящееся вне какой-то } \\
\text { формы) обучение, «встроенное» в течение жизни: осуществляемое } \\
\text { в ходе общения, происходящее под влиянием средств массовой } \\
\text { информации, просветительской акции, при чтении книг, при } \\
\text { осмыслении собственного опыта и опыта других. Университетами } \\
\text { становятся не только учебные аудитории и библиотеки, но и коллеги, } \\
\text { друзья, дети, средства массовой информации» }\end{array}$ & Обучение \\
\hline
\end{tabular}

${ }^{2}$ Словарь терминов. URL: http://inclusion.vzaimodeystvie.ru/inclusion/dictionary/\#Информальное_образование. 
Окончание табл.

\begin{tabular}{|c|c|c|}
\hline $\begin{array}{c}\text { Автор подхода, } \\
\text { источник информации }\end{array}$ & Определение понятия & Подход \\
\hline $\begin{array}{l}\text { О. А. Митусова (кан- } \\
\text { дидат педагогических } \\
\text { наук, профрессор) } \\
{[2, \text { с. 173] }}\end{array}$ & $\begin{array}{l}\text { Информальное образование - это «приобретение информации } \\
\text { с самых разных сторон - через средства массовой информации, } \\
\text { от коллег, знакомых, при посещении кино, театра и др. Та инфрорма- } \\
\text { ция, которую получает человек случайно, может быть } \\
\text { не всегда корректна, однако человек получил ее, т. е. продолжил } \\
\text { свое образование, хотел он этого или нет» }\end{array}$ & $\begin{array}{c}\text { Приоб- } \\
\text { ретение } \\
\text { информации }\end{array}$ \\
\hline $\begin{array}{l}\text { О.Р. Шувалова (кан- } \\
\text { дидат социологических } \\
\text { наук, заведующий от- } \\
\text { делом социологических } \\
\text { исследований Института } \\
\text { статистических иссле- } \\
\text { дований и экономики } \\
\text { знаний ГУ ВШЭ) [8] }\end{array}$ & $\begin{array}{l}\text { «Самообразование, или информальное обучение, - это нефор- } \\
\text { мальное индивидуальное обучение, которое в отличие от формаль- } \\
\text { ного образования и дополнительного образования осуществляется } \\
\text { самостоятельно и не фриксируется в дипломе или ином документе, } \\
\text { но вносит вклад в расширение знаний и умений». Таким образом, } \\
\text { происходит совмещение понятий инфоормального и неформального } \\
\text { видов образования }\end{array}$ & Обучение \\
\hline А. В. Окерешко [9] & $\begin{array}{l}\text { Информальное образование - «индивидуальная познавательная } \\
\text { деятельность, сопровождающая повседневную жизнь и не обяза- } \\
\text { тельно носящая целенаправленный характер, которая зачастую } \\
\text { создает предпосылки для включения в формальное и неформальное } \\
\text { образование, результатом чего является непрерывное личност- } \\
\text { но-профессиональное развитие человека. Главной идеей и целью } \\
\text { современной образовательной парадигмы становится идея грамот- } \\
\text { ной и плодотворной интеграции фрормального, неформального } \\
\text { и информального образования для наиболее успешной реализации } \\
\text { каждой личности» }\end{array}$ & Деятельность \\
\hline $\begin{array}{l}\text { Р.И. Юнацкевич } \\
\text { (заместитель директора } \\
\text { Института образования } \\
\text { взрослых Петровской } \\
\text { академии наук } \\
\text { и искусств, кандидат } \\
\text { технических наук) [10] } \\
\end{array}$ & $\begin{array}{l}\text { Информальное образование есть «результат повседневной рабо- } \\
\text { чей, семейной и досуговой деятельности, оно не имеет определен- } \\
\text { ной структуры и атрибутов педагогической формы (учебные планы, } \\
\text { образовательные программы и стандарты, планы и программы } \\
\text { просвещения, сценарии культурных мероприятий) и, как правило, } \\
\text { не приводит к сертификации» }\end{array}$ & $\begin{array}{c}\text { Результат } \\
\text { деятельности }\end{array}$ \\
\hline
\end{tabular}

Как показывают данные таблицы, можно выделить как минимум восемь подходов к определению понятия «информальное образование»:

1. Информальное образование как деятельность (подход зафиксирован в 2000 г. Меморандумом непрерывного образования ЕС. В Российской Федерации в настоящее время этого подхода придерживается такой автор, как А. В. Окерешко). Подход европейских ученых трактует понятие как специфически человеческую форму активности, обусловленную наличием сознания, не всегда имеющую целевой характер. Однако, по мнению российских ученых, деятельность это процесс активного взаимодействия, в котором есть объект и субъект, целеполагание, проектирование и осуществление действий, процесс последующего анализа результатов и сравнения их с плановыми задачами [11].

2. Информальное образование как результат деятельности (автор подхода - Р. И. Юнацкевич). Автор подхода акцентирует внимание на том, что это не столько сама деятельность, которая к тому же не имеет формализации, сколько ее результат.
3. Информальное образование как процесс ${ }^{3}$. Этот подход трактует понятие как фрилософрскую категорию, обозначающую: последовательную смену явлений, состояний в развитии; совокупность последовательных действий для достижения образовательной цели, результата.

4. Информальное образование как образование (Я. Кузьминов, И. Фрумин). Данный подход является самым широким, поскольку сам термин «образование» включает в себя множество аспектов: освоение определенных компетенций, получение знаний, умений, навыков, освоение культурного наследия, получение воспитания. Обращает на себя внимание акцент авторов подхода на спонтанности информального процесса образования и обязательном присутствии насыщенности среды, в котором оно осуществляется.

5. Информальное образование как обучение (авторы подхода - О. Р. Шувалова, С. Г. Вершловский). В целом обучение - это специально организованный, управляемый процесс целенаправленной передачи социального опыта. Авторы же анализируемого нами в данном случае подхода делают акцент

\footnotetext{
${ }^{3}$ Словарь терминов.
} 
на самостоятельности обучения в версии с информальным образованием и не столько на получении определенной суммы новых знаний, сколько на совершенствовании знаний, уже добытых индивидом.

6. Информальное образование как форма обучения (автор подхода - М. Тайт). В настоящее время в педагогической литературе не существует четкого понятия фрормы обучения. Однако можно встретить мнение, что это - деятельность, осуществляемая в определенном порядке и режиме. Следовательно, трактуя инорормальное образование как форму обучения, мы имеем дело со способом получения дополнительных знаний, умений и навыков в области изучения иностранного языка.

7. Информальное образование как приобретение информации (автор подхода О. А. Митусова). Считаем данный подход самым узким и самым размытым, поскольку дискуссии относительно того, что собой представляет научный термин «информация», ведутся учеными до сих пор, и взглядов на это понятие огромное множество, а единого определения, видимо, не появится никогда. Однако идея, передаваемая автором данного подхода, отражает мощное пассивное воздействие насыщенной окружающей среды на сознание и подсознание индивида, часто вне зависимости от его желания. Причем автор отмечает, что такое воздействие может быть не всегда корректным.

8. Информальное образование как жизненный опыт (авторы подхода - Ш. Мерриам, Р. Каффрарелла). Принимая во внимание глубину данного понятия и виды жизненного опыта, который получает индивид в процессе формирования своей биографии (бытовой, профрессиональный, религиозный, практический, армейский, ментальный, эмоциональный опыт и прочие его виды), можно констатировать тот факт, что данный подход является, пожалуй, самым обширным, дающим возможность усовершенствовать свое знание иностранного языка во всех возможных областях. Причем следует отметить, что зарубежные ученые больше склоняются к мнению о том, что информальное образование представляет собой именно деятельность, жизненный опыт, форму обучения, позволяющую человеку усваивать иностранный язык зачастую эффеектинее, чем во время академических занятий.

Таким образом, на основании всего вышеизложенного можно прийти к выводу, что понятие «информальное образование» в настоящее время очень активно исследуется педагогическим сообществом и рассматривается с разных точек зрения - философрской, лингвистической, педагогической и даже экономической, в рамках которой инорормальное образование рассматривается и как инструмент совершенствования человеческого капитала.

Информальное образование является сложной и многогранной категорией. Современные ученые показывают, что давать определение данному понятию необходимо, соотносясь с поставленными в нем задачами, и выделять именно тот аспект, который позволит достичь поставленной цели исследования.

Выявленные нами особенности информального образования в сравнении с формальным и неформальным видами образования, согласно взглядам отечественных и зарубежных ученых, занимающихся данным вопросом, позволяют констатировать тот факт, что информальное образование - это совокупность знаний, умений и навыков (общих и профессиональных образовательных компетенций), которые индивид получает в процессе повседневной деятельности на протяжении всей своей жизни, а следовательно, данный вид образования может быть определен как саморазвитие человека, мотивированное житейским любопытством, значимым примером, а также личностными качествами, такими как стремление к познанию нового, расширение кругозора, поиск ответов на проблемные вопросы и выходов из проблемных ситуаций, любознательность и внимательность. Определение содержит два подхода (педагогический и философский): информальное образование как набор образовательных компетенций и информальное образование как саморазвитие человека. Добавим, что рассматриваемый вид образования обладает следующими характеристиками: носит нецеленаправленный характер, не имеет определенной структуры и не нуждается в официальной сертификации.

В ходе изучения данного направления образования личности нам представляется необходимым обратить внимание также на взаимоотношения между понятиями «информальное образование» и «самообучение (самообразование)». Самообучение может рассматриваться как «целенаправленная, систематическая, автономная деятельность личности по добыванию, усвоению и творческой переработке знаний, предполагающая самостоятельность и независимость в выборе мотивов, целей, стиля поведения». Самообучение имеет некоторые общие черты и находится во взаимосвязи с такими процесса- 
ми, как самообразование, самостоятельная работа, самоорганизация. Самостоятельная работа готовит личность к самостоятельности и самоорганизации, которые, в свою очередь, являются основой самообучения. Личность, готовая к самообучению, сможет успешно заниматься самообразованием и достигать поставленных результатов. Рядом авторов понятие “самообразование» трактуется не только как процесс, но и как его результат, представляющий собой «сложное психологическое свойство личности, включающее два компонента: потребность в новых знаниях и в познавательных действиях». Оно формируется в процессе выполнения личностью определенной деятельности. Так, в структуре языкового образования в качестве такого свойства выступает коммуникативная деятельность на родном и иностранном языках. Согласно мнению Т. Ю. Тамбовкиной, овладевая коммуникативной деятельностью, «студент не всегда может самостоятельно выдвинуть ближайшие и отдаленные цели, поэтому данный процесс в значительной степени является объектом управления со стороны образовательной программы. Содержание образовательной программы во многом влияет на формирование у студента потребности в самообразовании». Получается, что самообразование все же подвергается некоему контролю и его характер нельзя назвать стихийным. Таким образом, мы видим, что информальное образование и самообучение (самообразование) не являются синонимичными единицами, хотя и предполагают наличие определенных сходных качеств личности и образовательных приемов/стратегий. Одним из таких важных элементов выступает мотивация студентов, их заинтересованность в выполняемой деятельности. Преподавателю необходимо помочь студенту перейти от формального мотива (выучить материал, чтобы не получить двойку) до осознанной самостоятельной познавательной деятельности (выполнить задание и изучить дополнительно те моменты, которые оказались непонятны, ранее неизвестны, привлекли внимание, которые являются актуальными). Нам представляется, что понятие «самообразование» несколько уже понятия «информальное образование» и может являться его частью.

Определение места и значения информального образования в процессе обучения в высшей школе также не составляет труда, поскольку его значение постоянно возрастает. Так, определяя место информального образования в процессе обучения студента языкового вуза, отметим, что учебным планом образовательной программы на самостоятельную работу по каждой дисциплине формально выделяется конкретное количество часов. Создаются условия для достижения максимально эффективного результата в рамках этого вида обучения: разрабатываются методические материалы (аннотации дисциплин, их рабочие программы, фронды оценочных средств); лингафонные кабинеты оснащаются специальным оборудованием, в них студенты проводят все больше времени помимо часов, отведенных на занятия с преподавателем; обеспечивается доступ в Интернет к программам, показывающим инновационные методики обучения иностранным языкам; организуются зарубежные языковые стажировки.

Говоря о месте информального образования в системе образования, необходимо также упомянуть о проблемных полях (проблемное поле науки, согласно социологическому словарю терминов, - это тематическое поле, совокупность всех тем и проблем, изучаемых текущей, существующей в данный момент наукой), с которыми приходится сталкиваться и которые должен проработать преподаватель, чтобы процесс обучения был наиболее плодотворным и позволял достичь существенных результатов в различных аспектах знания.

Проблемными полями информального образования нам представляются:

- низкая мотивация обучающихся к участию в информальном образовании;

- небольшой объем методических указаний для организации информального образования (непроработанность УМК на уровне компетентностного подхода);

- недостаточный объем словарного запаса и усвоенных грамматических средств для активного участия в информальном образовании.

Возрастающее значение информального образования в процессе обучения в высшей школе подчеркивает тот факт, что все вышеперечисленное позволяет современным студентам достичь лучшего теоретического и практического уровня знания иностранного языка, легкого усвоения его фонетических особенностей по сравнению с их предшественниками.

\section{СПИСОК ИСПОЛЬЗОВАННОЙ ЛИТЕРАТУРЫ}

1. Сженов Е. С. О разработке концепции непрерывного образования: основания и принципы / Е. С. Сженов // Высшее образование в России. - 2011. - № 2. - С. 93-98. 
2. Митусова О. А. Архитектоника и логико-смысловое содержание языкового образовательного пространства: формальное, неформальное, информальное образование студентов / О. А. Митусова // Государственное и муниципальное управление. Ученые записки СКАГС. — 2011. — № 3. - С. 171-176.

3. Золотухин С. А. Основы информального медийного обучения в педагогической среде [Электронный ресурс] / С. А. Золотухин, Бу Хунг // Ученые записки: электронный научный журнал Курского государственного университета. - 2013. - Т. 1, № 3 (27). - Режим доступа: http: / / www.scientific-notes. ru/pdf/031-024.pdf.

4. Российское образование - 2020: модель образования для экономики, основанной на знаниях : к 9-й междунар. науч. конф. «Модернизация экономики и глобализация», Москва, 1-3 апр. 2008 г. / под ред. Я. Кузьминова, И. Фрумина. - М. : Изд-во ГУ ВШЭ, 2008. - 39 с.

5. Tight M. Key Concepts in Adult Education and Training / M. Tight. — London : Routledge, 1996. - $208 \mathrm{p}$.

6. Merriam S. B. Learningin in Adulthood: a comprehensive guide / S. B. Merriam, R. S. Caffarella, L. M. Baumgartner. $-2^{\text {nd }}$ ed. - SanFrancisco : Jossey-Bass, 1999. $-376 \mathrm{p}$.

7. Образование взрослых: опыт и проблемы / под ред. С. Г. Вершловского. - СПб. : Знание, 2002. - 165 с.

8. Международные индикаторы участия населения в непрерывном образовании / подгот. О.Р. Шуваловой // Вопросы образования. - 2010. - № 2. - С. 178-186.

9. Окерешко А. В. Информальное образование: опыт определения понятия / А. В. Окерешко / / Академия профрессионального образования. — 2016. - № 1 (55). - С. 77-78.

10. Юнацкевич Р. И. Системное управление информальным образованием [Электронный ресурс] / Р. И. Юнацкевич // Институт образования взрослых. - Режим доступа: http://iovrao.spb.su/joomlalicense /407-2010-09-01-17-42-49.html.

11. Басов М. Я. Общие основы педологии / М. Я. Басов ; ред. Е. В. Левченко. - Изд. 3-е. - СПб. : Алетейя, 2007. $-776 \mathrm{c}$.

\section{REFERENCES}

1. Szhenov E. The concept of lifelong learning in modern Russia. Vysshee Obrazovanie $v$ Rossii $=$ Higher Education in Russia, 2011, no. 2, pp. 93-98. (In Russian).

2. Mitusova O. A. Architectonics and Logico-semantic Contents of the Language Educational Space: Formal, Non-formal, Informal Education of Students. Gosudarstvennoe i munitsipal'noe upravlenie. Uchenye zapiski SKAGS = State and Municipal Management Scholar Notes, 2011, no. 3, pp. 171-176. (In Russian).

3. Zolotukhin S. A., Khung Bu. Fundamentals of Informal Media Education in Pedagogical Environment. Uchenye zapiski: elektronnyi nauchnyi zhurnal Kurskogo gosudarstvennogo universiteta = Scientific Notes: electronic scientific journal of the Kursk State University, 2013, vol. 1, no. 3 (27). Available at: http: / /www. scientific-notes.ru/ pdf/031-024.pdf. (In Russian).

4. Kuz'minov Ya., Frumin I. (eds.). Rossiiskoe obrazovanie - 2020: model' obrazovaniya dlya ekonomiki, osnovannoi na znaniyakh. K 9-i mezhdunarodnoi nauchnoi konferentsii "Modernizatsiya ekonomiki i globalizatsiya», Moskva, 1-3 aprelya 2008 g. [Russian education-2020: Education model for a knowledge-based economy. In Proceedings of the $9^{\text {th }}$ International Scientific Conference "Modernization of the economy and globalization", Moscow, 1-3 April 2008]. Moscow, The Higher School of Economics Publ., 2008. 39 p.

5. Tight M. Key Concepts in Adult Education and Training. London, Routledge, 1996. 208 p.

6. Merriam S. B., Caffarella R. S., Baumgartner L. M. Learningin in Adulthood: a comprehensive guide. $2^{\text {nd }}$ ed. SanFrancisco, Jossey-Bass, 1999. 376 p.

7. Vershlovskii S. G. Obrazovanie vzroslykh: opyt i problemy [Adult Education: Experience and Problems]. Saint Petersburg, Znanie Publ., 2002. 165 p.

8. Shuvalova O. R. (ed.). International Indicators of Population Participation in Lifelong Learning. Voprosy obrazovaniya = Educational Studies, 2010, no. 2, pp. 178-186. (In Russian).

9. Okereshko A. V. Informal Education: Experience of Definition. Akademiya professional'nogo obrazovaniya = Academy of Professional Education, 2016, no. 1 (55), pp. 77-78. (In Russian).

10. Yunatskevich R. I. System Management of Informal Education. Institut obrazovaniya vzroslykh= Adult Education Institute. Available at: http: / /iovrao.spb.su/joomla-license/407-2010-09-01-17-42-49.html. (In Russian).

11. Basov M. Ya.; Levchenko E. V. (ed.). Obshchie osnovy pedologii [Fundamentals of Pedology]. $3^{\text {rd }}$ ed. Saint Petersburg, Aleteiya Publ., 2007. 776 p.

\section{Информация об авторах}

Лискина Тамара Владимировна - магистрант, кафедра лингвистики и межкультурной коммуникации, Институт иностранных языков Рязанского государственного университета им. С. А. Есенина, 390000, г. Рязань, ул. Свободы, 46, e-mail: listpismo@ mail.ru.

Паульзен Наталья Сергеевна - кандидат фрилологических наук, доцент, кафедра иностранных языков, Институт мировой экономики и международных отношений Байкальского государственного университета, 664003, г. Иркутск, ул. Ленина, 11, e-mail: alla_po@mail.ru

\section{Authors}

Tamara V. Liskina - Master's Degree student, Department of Linguistics and Cross-Cultural Communication, Institute of Foreign Languages at S. A. Yesenin Ryazan State University, 46 Svobody St., 390000, Ryazan, the Russian Federation, e-mail: listpismo@mail.ru.

Natalia S. Paulsen - PhD in Philology, Associate Professor, Department of Foreign Languages, Institute of World Economy and International Relations, Baikal State University, 11 Lenin St., 664003, Irkutsk, the Russian Federation, e-mail: alla_po@mail.ru. 


\section{Для цитирования}

Лискина Т. В. Современные подходы к определению понятия «информальное образование» / Т. В. Лискина, Н. С. Паульзен // Известия Байкальского государственного университета. - 2018. T. 28, № 1. - C. 131-137. - DOI: 10.17150/25002759.2018.28(1).131-137.

\section{For citation}

Liskina T. V., Paulsen N. S. Modern Approaches to the Definition of «Informal Education». Izvestiya Baykal' skogo gosudarstvennogo universiteta $=$ Bulletin of Baikal State University, 2018, vol. 28, no. 1, pp. 131137. DOI: $10.17150 / 2500-2759.2018 .28(1) .131-137$. (In Russian). 